\title{
Hubungan Antara Gaya Belajar dengan Hasil Belajar IPS Siswa Kelas VIII SMP Negeri 2 Demak
}

\section{Fatrikha Najma Untsa, Tukidi, Fredy Hermanto ${ }^{\bowtie}$}

Social Science Education Department, Faculty of Social Science, Universitas Negeri Semarang, Indonesia

\section{Info Artikel}

Sejarah Artikel:

Disubmit:

Direvisi:

Diterima:

\section{Keywords:} learning style; learning outcomes; social studies learning

\begin{abstract}
Abstrak
Seorang pendidik seharusnya dapat menyadari bahwa setiap anak memiliki perbedaan gaya belajar. Dengan mengetahui gaya belajar siswa, guru dapat mengakomodasikan berbagai metode pembelajaran menyesuaikan dengan kebutuhan siswa. Sehingga semua siswa dapat memperoleh cara yang efektif dalam belajarnya. Penelitian ini dilakukan di SMP Negeri 2 Demak sebagai subjek penelitian dengan tujuan untuk mengetahui hubungan antara gaya belajar dengan hasil belajar IPS siswa kelas VIII SMP Negeri 2 Demak. Populasi dalam penelitian ini yaitu seluruh siswa kelas VIII A-J yang berjumlah 338 siswa dan sampel sebanyak 138 siswa dengan menggunakan teknik random sampling. Pengumpulan data gaya belajar dengan menggunakan angket, sedangkan hasil belajar IPS diambil dari nilai rapot semester genap tahun ajaran $2017 / 2018$. Data yang diperoleh dihitung dengan rumus anova dengan taraf signifikansi 5\%, sehingga nilai $\mathbf{F}_{\boldsymbol{h}}$ 3,29 $>\mathbf{F}_{\boldsymbol{t a b}}$ 3,05 artinya $\boldsymbol{H}_{\boldsymbol{a}}$ diterima. Hal ini menunjukkan bahwa terdapat hubungan yang positif antara gaya belajar dengan hasil belajar IPS siswa.
\end{abstract}

\begin{abstract}
An educator should be able to realize that every student has different learning styles. By knowing the student's learning style, the teacher can accommodate various learning methods to suit the needs of students. So that all students can get effective ways of learning. This research was conducted in SMP Negeri 2 Demak as a research subject with the aim of finding out the relationship between learning styles with the results of social studies learning of eighth grade students of SMP Negeri 2 Demak. The population in this study were all students of class VIII A-J totaling 338 students and a sample of 138 students using random sampling technique. Collecting learning style data using questionnaires, while social studies learning outcomes are taken from the rapot value of the even semester of 2017/2018 school year. The data obtained is calculated by anova formula with a significance level of 5\%, so that the value of $F_{-} h 3.29>F_{\text {_tab }} 3.05$ means that $H_{-}(a)$ is accepted. This shows that there is a positive relationship between learning styles and student social studies learning outcomes.
\end{abstract}




\section{PENDAHULUAN}

Pendidikan sangat dibutuhkan pada era modern ini, karena pendidikan berperan penting dalam mempersiapkan sumber daya manusia yang berkualitas. Melalui pendidikan berbagai aspek kehidupan dikembangkan dengan proses belajar dan pembelajaran. Menurut Hilgard, belajar adalah proses perubahan melalui kegiatan atau prosedur latihan baik latihan di dalam labolatorium maupun dalam lingkungan alamiah (Sanjaya, 2008 : 229).

Belajar tidak hanya untuk mengumpulkan pengetahuan. Belajar merupakan sebuah proses yang terJadi, pada diri seseorang. Dalam menjalankan proses belajar siswa memiliki gaya tersendiri yang biasa di kenal dengan istilah "gaya belajar". Menurut Susilo (2009:94) gaya belajar merupakan cara yang cenderung dipilih seseorang untuk menerima informasi dari lingkungan dan memproses informasi tersebut. Bobbi De Porter \& Mike Hernacki (2007:110) memperkenalkan modalitas belajar yang terdiri dari visual, auditory, and kinesthetic. Gaya belajar visual artinya belajar melalui apa yang siswa lihat, gaya belajar auditorial berarti belajar melalui apa yang siswa dengar, dan gaya belajar kinestetik artinya belajar lewat gerak dan sentuhan. Menurutnya siswa yang memahami modalitas belajarnya sendiri maka akan memperoleh manfaat tentang bagaimana cara belajar yang cocok bagi dirinya sendiri. Sehingga semua siswa dapat memperoleh cara yang efektif dalam belajarnya.

Mata pelajaran Ilmu Pengetahuan Sosial membahas hubungan antara manusia dengan lingkungannya. Ilmu Pengetahuan Sosial (IPS) SMP/MTs merupakan integrasi dari berbagai disiplin ilmu-ilmu sosial seperti: Geografi, Sosiologi, Sejarah, dan Ekonomi. Rumusan Ilmu Pengetahuan Sosial berdasarkan realitas dan fenomena sosial melalui pendekatan interdisipliner. Adapun tujuan utama Ilmu Pengetahuan Sosial adalah untuk mengembangkan potensi siswa agar peka terhadap masalah sosial yang terJadi, di lingkungan masyarakat, memiliki sikap mental yang positif, dan terampil dalam mengatasi masalah yang terJadi, sehari-hari.

Hasil belajar siswa merupakan komponen yang paling penting dalam kegiatan pembelajaran. Sehingga guru bertugas untuk mengukur berdasarkan penguasaan ilmu yang dipelajari oleh siswa sesuai dengan tujuan yang di rumuskan. Astuti dkk (2012:2) menyatakan bahwa "Pada dasarnya pengertian hasil belajar dengan prestasi adalah sama. Prestasi belajar merupakan bagian dari hasil belajar....Prestasi belajar siswa adalah hasil belajar yang dicapai siswa ketika mengikuti dan mengerjakan tugas dan kegiatan pembelajaran disekolah yang ditunjukan dengan nilai atau angka sesuai batas ketuntasan minimum yang telah ditetapkan oleh sekolah". Menurut Benyamin S. Bloom, dkk hasil belajar dapat dikelompokkan ke dalam tiga domain, yaitu kognitif, afektif, dan psikomotor.

Selama ini guru belum mampu untuk mengenali gaya belajar siswa pada mata pelajaran IPS secara spesifik dan menyeluruh. Apabila gaya belajar yang biasa dilakukan oleh siswa dirubah atau dipaksa dengan gaya belajar yang lain maka dapat menyebabkan tidak optimalnya informasi atau pengetahuan yang akan diperoleh siswa tersebut. Dengan demikian, dapat berdampak pada hasil belajar siswa yang menurun.

Berdasarkan hal tersebut, peneliti tertarik untuk melakukan penelitian dengan judul "Hubungan antara Gaya Belajar dengan Hasil Belajar IPS Siswa Kelas VIII SMP Negeri 2 Demak". Hal ini bertujuan untuk mengetahui gaya belajar yang dimiliki siswa dan perolehan hasil belajar IPS siswa kelas VIII SMP Negeri 2 Demak.

\section{METODE}

Penelitian ini menggunakan penelitian kuantitatif dengan menggunakan metode Expost Facto. Metode penelitian Ekspos Facto dapat diartikan sebagai metode penelitian yang digunakan untuk mencari pengaruh variabel tertentu terhadap yang lainnya dalam kondisi waktu tertentu. 
Populasi dalam penelitian ini adalah siswa kelas VIII A - J SMP Negeri 2 Demak dengan jumlah 338 siswa. Teknik sampling menggunakan simple random sampling dengan jumlah sampel 183 siswa.

Data penelitian diperoleh melalui angket gaya belajar yang telah diuji validitas dan reliabilitas. Sedangkan data hasil belajar diperoleh melalui dokumentasi pada nilai rapot kelas VIII yang terdiri dari tiga ranah (kognitif, afektif, dan psikomotor).

Teknik analisis data untuk mengetahui hipotesis menggunakan uji anova, sebelum melakukan uji anova maka perlu dilakukan uji homogenitas terlebih dahulu. Jika harga F_(hitung ) $<$ dari F_tabel dengan tingkat kesalahan 5\% maka data tersebut bersifat homogen. Sedangkan dalam perhitungan anova pengambilan keputusan agar H_(a )diterima maka F_hitung 『>F』_tab untuk kesalahan $5 \%$.

\section{HASIL DAN PEMBAHASAN}

Data untuk penelitian ini diambil dari kelas VIII A-J dengan sampel 183 siswa. Berdasarkan hasil perhitungan angket gaya belajar menunjukkan bahwa bahwa siswa yang memiliki gaya belajar visual sebanyak 64 siswa, siswa yang memiliki gaya belajar auditorial sebanyak 92 orang, sedangkan siswa yang memilik gaya belajar kinestetik sebanyak 27 siswa.

Tabel 1. Persentase Gaya Belajar Siswa

\begin{tabular}{lll}
\hline No. & $\begin{array}{c}\text { Jenis Gaya } \\
\text { Belajar }\end{array}$ & \multicolumn{1}{c}{$\begin{array}{c}\text { Persentase Gaya } \\
\text { Belajar }\end{array}$} \\
\hline 1. & Visual & $\frac{\mathbf{6 4}}{\mathbf{1 8 3}} \times \mathbf{1 0 0} \%=$ \\
& & $\mathbf{3 4 ,}, \mathbf{9 7} \%=35 \%$ \\
2. & Auditorial & $\frac{\mathbf{9 2}}{\mathbf{1 8 3}} \boldsymbol{x} \mathbf{1 0 0} \%=$ \\
& & $\mathbf{5 0 , 2 7} \%=50 \%$ \\
3. & Kinestetik & $\frac{\mathbf{2 7}}{\mathbf{1 8 3}} \boldsymbol{x} \mathbf{1 0 0} \%=$ \\
& & $\mathbf{1 4 , 7 5} \%=15 \%$ \\
\hline
\end{tabular}

Sumber: Data primer, 2018
Tabel 2. Kategorisasi Gaya Belajar

\begin{tabular}{cllll}
\hline No & $\begin{array}{l}\text { Interva } \\
1\end{array}$ & $\begin{array}{l}\text { Frekuens } \\
\mathrm{i}\end{array}$ & $\begin{array}{l}\text { Persentas } \\
\mathrm{e}(\%)\end{array}$ & $\begin{array}{l}\text { Kategor } \\
\mathrm{i}\end{array}$ \\
\hline & $>16$ & 11 & 6,01 & Sangat \\
& & & Baik \\
& $12-16$ & 137 & 74,86 & Baik \\
$<12$ & 35 & 19,13 & Cukup \\
Jumlah & 183 & 100,00 & \\
\hline
\end{tabular}

Sumber: Data primer, 2018

Tabel 1 menunjukkan bahwa siswa kelas VIII SMP Negeri 2 Demak sebagian besar memiliki gaya belajar auditorial. Sedangkan pada tabel 2 menginformasikan bahwa gaya belajar siswa kelas VIII SMP Negeri 2 Demak termasuk ke dalam kategori baik yaitu sebesar $75 \%$.

Hasil belajar IPS diukur dengan menggunakan data hasil dokumentasi nilai rapor kelas VIII pada semester genap tahun ajaran 2017/2018. Data hasil belajar ini terdiri dari tiga ranah yaitu hasil belajar ranah kognitif, ranah afektif dan hasil belajar pada ranah psikomotor.

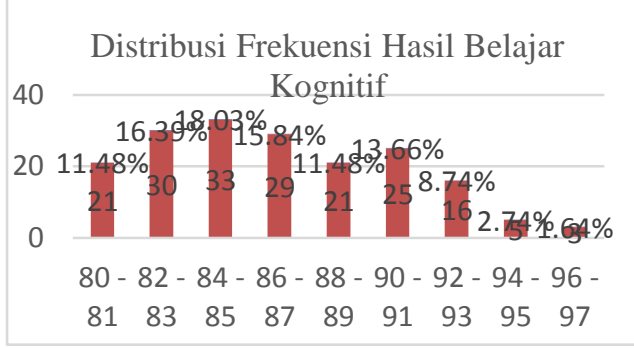

Gambar 1. Histogram Hasil Belajar Kognitif

Gambar 1. menunjukkan bahwa frekuensi hasil belajar kognitif paling banyak terletak pada interval 84 - 85 sebanyak 33 siswa (18,03\%) dan paling sedikit terletak pada interval $96-97$ sebanyak 3 siswa (1,64\%).

Tabel 3. Kategorisasi Hasil Belajar Kognitif

\begin{tabular}{ccccl}
\hline $\begin{array}{l}\mathrm{N} \\
\text { o. }\end{array}$ & $\begin{array}{l}\text { Interv } \\
\text { al }\end{array}$ & $\begin{array}{l}\text { Frekue } \\
\text { nsi }\end{array}$ & $\begin{array}{l}\text { Persentase } \\
(\%)\end{array}$ & Kategori \\
\hline & $>91$ & 24 & 13,12 & $\begin{array}{l}\text { Sangat } \\
\text { Baik }\end{array}$ \\
& & & Baik \\
91 & 75 & 40,98 & Cukup \\
$<86$ & 84 & 45,90 & \\
\hline
\end{tabular}

Sumber: Data primer, 2018 
Tabel 3 menginformasikan bahwa siswa SMP Negeri 2 Demak pada hasil belajar IPS ranah kognitif memiliki kategori sangat baik sebanyak 24 siswa (13\%), kategori baik 75 siswa (41\%) dan hasil belajar kategori cukup sebanyak 84 siswa (46\%). Jadi, dapat disimpulkan bahwa, kecenderungan variabel hasil belajar IPS siswa ranah kognitif berada pada kategori cukup yaitu sebanyak 84 siswa (46\%).

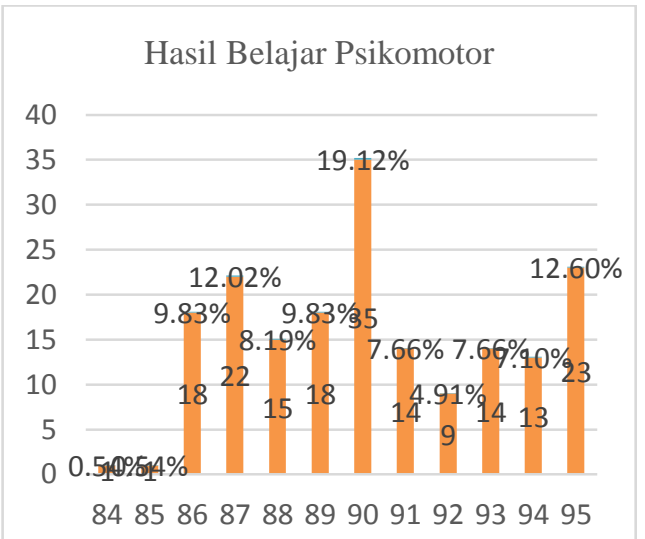

Gambar 2. Histogram Hasil Belajar Psikomotor

Gambar 2. Menginformasikan bahwa frekuensi hasil belajar psikomotor paling banyak terletak pada interval 90 sebanyak 35 siswa $(19,12 \%)$ dan paling sedikit terletak pada interval 84 dan 85 sebanyak 1 siswa (0,54\%).

Tabel 4. Kategorisasi Hasil Belajar Psikomotor

\begin{tabular}{cllll}
\hline $\begin{array}{l}\text { No } \\
.\end{array}$ & $\begin{array}{l}\text { Inter } \\
\text { val }\end{array}$ & $\begin{array}{l}\text { Freku } \\
\text { ensi }\end{array}$ & $\begin{array}{l}\text { Persentase } \\
(\%)\end{array}$ & Kategori \\
\hline & $>91$ & 59 & 32,25 & $\begin{array}{l}\text { Sang-at } \\
\text { Baik }\end{array}$ \\
$88-91$ & 82 & 44,80 & Baik \\
$<88$ & 42 & 22,95 & Cukup \\
Jumlah & 183 & 100,00 & \\
\hline
\end{tabular}

Tabel 4. menunjukkan bahwa siswa SMP

Negeri 2 Demak pada hasil belajar IPS ranah psikomotor siswa yang memiliki kategori sangat baik sebanyak 59 siswa (32\%), kategori baik 82 siswa (45\%) dan hasil belajar kategori cukup sebanyak 42 siswa (23\%). Jadi, dapat disimpulkan bahwa, kecenderungan variabel hasil belajar IPS siswa berada pada kategori sangat baik yaitu sebanyak 84 siswa (45\%).

Hasil belajar ranah afektif pada nilai rapor kelas VIII menginformasikan bahwa sebagian besar siswa yaitu berjumlah $156 \quad(85,25 \%)$ memiliki nilai sikap yang baik dan 27 (14,75\%) siswa memiliki sikap yang sangat baik. Penilaian sikap tersebut berdasarkan pada beberapa aspek seperti sikap menghargai, menghayati, jujur, disiplin, tanggung jawab, peduli, santun, dan percaya diri.

Berdasarkan hasil tersebut dapat diambil kesimpulan bahwa subjek dalam penelitian yaitu siswa kelas VIII SMP Negeri 2 Demak memiliki hasil belajar IPS dalam kategori cukup pada ranah kognitif yaitu sebesar $46 \%$ dan dalam kategori baik pada ranah psikomotor yaitu sebesar $45 \%$, serta memiliki sikap yang baik yaitu sebesar $85 \%$.

\section{Pengujian Hipotesis}

Data yang diperoleh kemudian diuji hipotesisnya dengan menggunakan uji anova. Sebelum anova digunakan untuk pengujian hipotesis, maka perlu diuji homogenitas. Berdasarkan hasil hitung dengan bantuan tabel penolong menunjukkan bahwa $\boldsymbol{F}_{\text {hitung }} 1,40<$ $\boldsymbol{F}_{\text {tabel }}$ 1,50 sehingga data tersebut bersifat homogen.

Selanjutnya untuk perhitungan anova dalam pengambilan keputusan agar $\boldsymbol{H}_{\boldsymbol{a}}$ diterima maka $\mathbf{F}_{\text {hitung }}>\mathbf{F}_{\text {tab }}$ untuk kesalahan 5\%. Berdasarkan perhitungan hipotesis yang diperoleh melalui uji anova menginformasikan bahwa $\mathbf{F}_{\boldsymbol{h}}$ 3,29 $>\mathbf{F}_{\boldsymbol{t a b}}$ 3,05 sehingga $\boldsymbol{H}_{\boldsymbol{a}}$ diterima. Ini menyatakan bahwa variabel gaya belajar berhubungan positif dengan hasil belajar siswa kelas VIII SMP Negeri 2 Demak. Hal tersebut sesuai dengan yang dikatakan oleh Dunn \& Dunn yang dikutip oleh Sugihartono (2007), bahwa siswa yang dapat mengetahui dan memaksimalkan gaya belajar yang dimilikinya akan membuat suatu pembelajaran menjadi, efektif. Dengan demikian, sebaiknya siswa dapat mengetahui gaya belajarnya dan guru juga diharapkan dapat mengenali gaya belajar siswanya agar dapat mencapai tujuan pembelajaran. 


\section{SIMPULAN}

Hasil penelitian dan pembahasan mengenai hubungan antara gaya belajar dengan hasil belajar IPS siswa kelas VIII SMP Negeri 2 Demak dapat disimpulkan bahwa gaya belajar yang digunakan siswa kelas VIII SMP Negeri 2 Demak yaitu gaya belajar auditorial yang mana siswa lebih mudah memahami materi dengan cara mendengarkan. Sedangkan pada variabel hasil belajar IPS siswa ranah kognitif berada pada kategori cukup yaitu sebanyak 84 siswa (46\%), pada ranah afektif sebagian besar siswa yaitu berjumlah $156(85,25 \%)$ memiliki nilai sikap yang baik, dan pada ranah psikomotor sebagian besar siswa termasuk ke dalam kategori baik yaitu sebanyak 82 siswa (45\%).

Saran kepada siswa-siswa SMP Negeri 2 Demak hendaknya dapat mengetahui gaya belajar yang dimilikinya, karena dengan gaya belajar tersebut akan mempermudah dalam memahami materi yang dipelajarinya. Selain itu, saran untuk guru, hendaknya mendukung gaya belajar yang dimiliki oleh siswanya dan juga dapat mengakomodasikan berbagai metode pembelajaran menyesuaikan dengan kebutuhan siswa. Sehingga siswa mendapatkan hasil belajar IPS yang maksimal

\section{DAFTAR PUSTAKA}

Astuti, Wiwin Wiji, dkk.2012. Pengaruh Motivasi Belajar dan Metode Pembelajaran Terhadap Hasil Belajar IPS Terpadu Kelas VIII SMP PGRI 16 Brangsong Kabupaten Kendal. Dalam Jurnal Economic Education Analysis Journal. Vol.1. Hal 2-6.

De Potter, Bobbi \& Mike Hernacki.2007.Quantum Learning: membiasakan belajar nyaman dan menyenangkan. Bandung: Kaifa.

Sanjaya, Wina.2008.Kurikulum dan Pembelajaran. Jakarta: Kencana.

Susilo, Joko.2009.Sukses dengan Gaya Belajar. Yogyakarta: Pinus. 